PROBLEMS

OF MANAGEMENT

IN THE $21^{\text {st }}$ CENTURY

Volume 5, 2012

\title{
RESPONSIBILITY FOR MANAGEMENT
}

\author{
Vincentas Lamanauskas \\ University of Šiauliai, Lithuania \\ E-mail: v.lamanauskas@ef.su.It
}

Business is neither a new branch of science, nor a recently emerged social or political phenomenon. We are not tend to discuss the history of management as obviously this field like many other activities stimulated by human includes own origin, gained experience and a certain retrospective. A modern world has strongly developed the concept of management thus becoming an integral and manifold idea. A number of published articles, text/books, recommendations, etc. represent different levels of writing. Moreover, corrections and supplements are made to the already available management theories and conceptions the new versions of which are also successfully created. The present structure of studies at university can be hardly imagined without varying courses on the subjects related to management. For the last two decades, the majority of countries around the world have faced the young generation engaged in management sciences; after graduating secondary school, a relatively large part of the youth keep on studying management sciences, i.e. a strong tendency reveals that graduates prefer social sciences and humanities. The reasons for motivation may vary. However, more frequently expressed opinions are those stating that such choice can be simply influenced by laziness experienced by a part of students, willingness to try, overcome difficulties, etc. Despite a notable lack of professionals in the field in technological sciences in a large part of countries, quite a few learners are greatly interested in social sciences. Supposedly, such choice can be the result of the existing stereotypes and rational motivation (less complicated entry to a university, easier studies, etc.). Lengthy discussions are inappropriate due to the fact that in-depth research on dominant motifs is required. This is important because today's young people are would-be leaders and managers and the degree of their motivation, purposeful choice and responsibility will affect not only the well-being of a certain organization but also that of particular society.

The factor in responsibility considering the structure of management should gain the required weight. The success of organizations is determined not only by a properly prepared strategy (frequently in a 'paper version'), optimal structure, precisely and effectively organized processes, but also taking into account the responsibility of particular people at various levels of management. Nevertheless, the above introduced issues are not paid enough attention - a more common option is considering the questions of management at the level of organizations. Meanwhile, a discussion on responsibility, first of all, must evaluate the competencies of a one or another manager. In a complete scale of managing competencies, responsibility should serve as an integrating and effective element. The worldwide known Japanese manager Kazuo Imamura (2006) stated that 'to be the right man, he was striving for things appropriate for everyone'. It seems to be clear there are opposing positions pointing to different theories investigating the phenomenon and expression of responsibility in management. Perhaps modern rather than useful concepts of social responsibility should be mentioned, which has become especially noticeable for the last few years. Plenty of enterprises and organizations find themselves socially responsible thus discussing and making such information publically available. Moreover, the main argument put forward by such organizations suggests this is the way of how they are 
involved in the development of sustainable society. From a systemic point of view, all theories, concepts, laws, etc. are formed and described in scientific writings, and, as a rule, are only valid for ideal systems under ideal circumstances. However, reality is different, and therefore real systems considerably differ from the ideal ones. Next, the majority of theories and laws are logically cannot be applied for such systems, particularly for those designed for management purposes. These can include not only non-linear systems, but also heterogeneous, multicriteria, multi-parametrical, etc. What is the degree of the social responsibility of enterprises and organizations for the actions taken if they are primarily focused on expressing the interests of the clients and/or shareholders? We cannot accept responsibility as such due to the fact that profit-chasing by any means frequently becomes the action of priority.

Thus, management becomes more up-to-date and faces a crisis that sparks off increased pace at work, different pressure, hardly understandable orders, stress and even suicides at the workplace. Although recently these issues are frequently discussed, still, it is not sufficient. Some of the methods for management are frequently accepted as making a negative impact on the physical and psychological state of the employees despite the fact that they appear to be efficient tools in terms of increased profit. Only discussions cannot solve this problem, which clearly indicates a lack of in-depth and reliable scientific research in the field.

Responsibility is obviously directly related to values. Various crises of economy frequently arising in different parts of the world are often determined by the consistent patterns of managerial economics and the so-called human factor (Lamanauskas, 2011). Management is not unfettered freedom to generate profit or other material resources taking advantage of other people. According to C. Dierksmeier (2011), more and more frequently we discuss about the constructive use of the idea of responsible freedom. Certainly, a good manager is the one who has a broad knowledge of management theories and demonstrates practical abilities and skills. A gift of speech, pleasant appearance, good manners of behaviour and finally information on the nuances of management ethics are not enough. Traditionally, work done by a manager is complex and highly responsible and can be carried out by the one who has gained the required amount of knowledge and skills at management. It is reasonable to admit that the field of management can (should) only be properly acknowledged by those having a high level of responsibility perceived as one of fundamental values. Knowledge about and skills at management can be successfully acquired. Hence, the saying that 'a good manager is worth a golden bar' really makes sense.

\section{References}

Dierksmeier, C. (2011). The Freedom-Responsibility Nexus in Management Philosophy and Business Ethics. Journal of Business Ethics, 101 (2), 263-283.

Inamori, K. (2006). Gyvenimo filosofija. Vilnius: Versus aureus.

Lamanauskas, V. (2011). Perspective Management: Systemic Thinking and Value Synergy Necessity. Problems of Management in the 21st Century (Topical Issues in Management - 2011), 1, 5-6.

$\begin{array}{ll}\text { Vincentas Lamanauskas } & \text { PhD., Professor, Siauliai University, Natural Science Education Research Cen- } \\ & \text { tre, 25-119 P. Višinskio Street, LT- 76351, Siauliai, Lithuania. } \\ & \text { E-mail: lamanauskas@lamanauskas.puslapiai.It } \\ & \text { Website: http://www.lamanauskas.puslapiai.It }\end{array}$

